\title{
Lusioersily
}

\section{Smart Wireless Continence Management System for Patients with Dementia}

Aung, APW., Fook, VFS., Jayachandran, M., Biswas, J., Zheng, S., Nugent, CD., Mulvenna, M., Lee, JE., \& Yap, P. (2008). Smart Wireless Continence Management System for Patients with Dementia. In Proceedings IEEE 10th International Conference on e-Health Networking, Application \& Services (HealthCOM-2008) (pp. 33-34). IEEE. https://doi.org/10.1109/HEALTH.2008.4600105

Link to publication record in Ulster University Research Portal

\section{Published in:}

Proceedings IEEE 10th International Conference on e-Health Networking, Application \& Services (HealthCOM2008)

\section{Publication Status:}

Published (in print/issue): 01/07/2008

DOI:

10.1109/HEALTH.2008.4600105

\section{Document Version}

Publisher's PDF, also known as Version of record

\section{General rights}

Copyright for the publications made accessible via Ulster University's Research Portal is retained by the author(s) and / or other copyright owners and it is a condition of accessing these publications that users recognise and abide by the legal requirements associated with these rights.

\section{Take down policy}

The Research Portal is Ulster University's institutional repository that provides access to Ulster's research outputs. Every effort has been made to ensure that content in the Research Portal does not infringe any person's rights, or applicable UK laws. If you discover content in the Research Portal that you believe breaches copyright or violates any law, please contact pure-support@ulster.ac.uk. 


\title{
Smart Wireless Continence Management System for Elderly with Dementia
}

\author{
Aung Aung Phyo Wai ${ }^{1}$, Foo Siang Fook ${ }^{1}$, Maniyeri Jayachandran ${ }^{1}$, Zheng Song ${ }^{1}$, Jit Biswas ${ }^{1}$, Chris Nugent ${ }^{2}$, Maurice \\ Mulvenna ${ }^{2}$, Jer-En Lee ${ }^{3}$, Lin Kiat Philip Yap ${ }^{3}$ \\ ${ }^{1}$ Institute for Infocomm Research, Singapore \\ \{apwaung, sffoo, mjay, szheng, biswas\}@i2r.a-star.edu.sg \\ ${ }^{2}$ University of Ulster, Belfast, Northern Ireland, UK \\ \{cd.nugent, md.mulvenna\}@ulster.ac.uk \\ ${ }^{3}$ Alexandra Hospital, Singapore \\ \{jer_en_lee, philip_yap\}@alexhosp.com.sg
}

\begin{abstract}
Elderly patients, especially those with dementia may suffer incontinence and related problems due to decline in physical and mental abilities. This paper presents the design, development and deployment of a smart wireless continence management system in a nursing home which addresses the pressing need for reliable continence assessment to alleviate the inconveniences faced by the elderly and caregivers. Preliminary results are promising for long-term incontinence care.
\end{abstract}

Keywords- incontinence, smart continence management system, wireless sensor network, elderly with dementia

\section{INTRODUCTION}

Urinary incontinence [1], defined as "the complaint of any involuntary leakage of urine that is socially undesirable", is highly prevalent among elderly especially those with dementia. It is a distressing and costly health problem that affects not only the elderly but also the caregivers. A study [2] done in Singapore shows that about $9.2 \%$ of elderly people above 65 years old across the nation required incontinence aids, and more than $50 \%$ of those residing in nursing homes or institutions suffer from various incontinence related problems.

Currently, the common practice for continence management is very labor intensive and involves the caregivers having to conduct periodic checks leading to unnecessary visits and delayed response. If there is a delay in responding to the need for diaper change following an episode of urinary incontinence, it will lead to a situation where the patient lies in soiled diapers for a long period that may cause from discomfort, anxiety, distress to possible skin breakdown and bedsores. Hence there is an urgent need to find alternative solutions to the problem of incontinence.

In this paper, we present the design, development, deployment and evaluation of a smart wireless continence management system for elderly with dementia in a local nursing home. The system supports automated timely detection of an incontinence episode and a gradual shift from the existing manual procedure to an automated care management that will enhance the quality of care.

\section{SYSTEM DESIGN AND DEVELOPMENT}

Prior to designing the system, surveys were conducted on existing products and research prototypes related to incontinence care. Majority of the existing commercial products $[3,4]$ are targeted at children for self toilet training and operate in standalone unit only. Though there are some active research projects $[5,6]$ on enuresis sensors for wetness detection, there is limited work done for dementia elderly with incontinence problems, either to alleviate patients' or caregivers' problems, or to mitigate the problem through controlled voiding in term of a holistic continence management system.

In order to understand the real needs for managing incontinence, we have hold numerous discussions with doctors, caregivers, nursing staffs and patients at hospital or nursing homes, taking into consideration the requirements for providing quality incontinence care. A questionnaire survey was also conducted with caregivers from two nursing homes to investigate theirs views on the needs to perform diaper change within a timely automated manner. From healthcare viewpoints, we found that the sensor type, sensor size, cost, reusability and safety issues are important factors to be considered, and from technology viewpoint, we have to consider factors such as robustness, extensibility, coverage area and personalized intervention.

We design a smart wireless continence management system based on the pervasive mote wireless platform [7] whereby alerts such as call bell or SMS could be automatically triggered once a diaper is wet using wetness sensors, prompting the need for a diaper change. It supports the deployment of potentially large quantities of wetness sensors with wider coverage and with dramatically less complexity and cost, and once turned on, it can be self-organizing. It also consists of intelligent relay mechanism so that the residents are free to move about in the nursing home, and allows personalized continence management service. Figure 1 shows an overview of the smart wireless continence management system. It consists of the sensor nodes, relay nodes, gateway node, actuator nodes, SMS gateway, CmsController server, etc. The sensor node, composed of a wetness sensor and transmitter, will detect and 
report the wetness event. The relay and actuator nodes are colocated, and will relay message and notify the caregivers through a buzzer and a set of LEDs once urine is detected respectively. The gateway node is connected to the CmsController server through an Ethernet programming board. The server consists of intelligence which acts as a bridge between the sensor network and user applications.

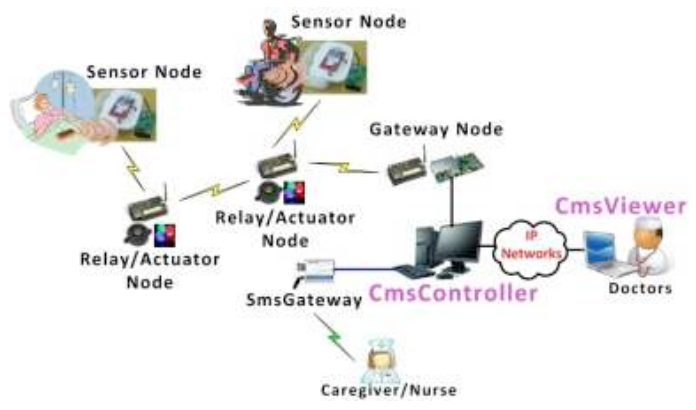

Figure 1. Smart Wireless Continence Management System

The operation of the system is kept simple with minimum users' intervention. First, the caregivers need to place the sensing node inside the patient's diaper. The system will automatically notify the caregivers through appropriate alerts such as buzzers, LEDs, SMS and 3D user interfaces once a wetness event is detected. The caregiver clicks the "Replace Diaper" user interface on the server and re-starts the whole process for another monitoring. The system was tested in the laboratory by simulating real world scenarios. We can achieve a detection rate of up to $100 \%$ with no false alarm.

\section{Nursing Home Trials \& RESUlts}

We decide to conduct a trial in a nursing home after conducting many experiments in the laboratory. As a start, we perform the trial with a suitable single elderly with high continence aid requirements. We hope to continue to tune the system for robustness before we conduct a bigger trial with more elderly. The sensor-signal receiver node was deployed in the vicinity of the patient such as on the bedside or the wheelchair. Two relay/actuator nodes were placed outside the patients' room and near the common dining area respectively. The gateway node was placed outside the nursing station, and the PC with 3D user interface was installed in the nursing station for the caregivers to monitor incontinence status and interact with the system when an incontinence episode occurs. Figure 2 shows the actual deployment in the nursing home.
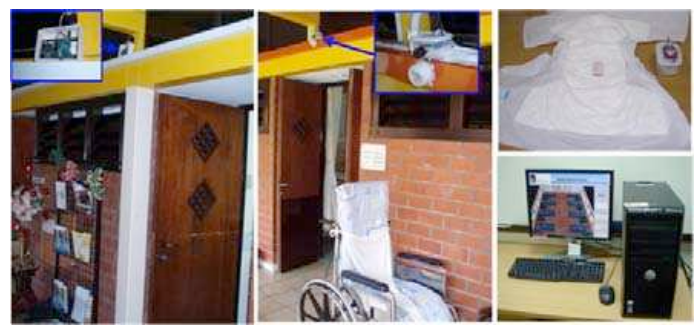

Figure 2. System Deployments in Nursing Home
Preliminary results after a few weeks trial are very encouraging as the system works fine in term of robustness and stability, and the wetness event can be detected. There is no single false alarm throughout the trial though the detection rate is not as good as what we expected compared to the mock up we have done before the deployment in which it can reach up to $100 \%$ detection rate. We found that the problems are due to the location of the wetness sensor that is being put in the diaper unit and human factors such as improper user handling of the sensor and system. We are still trying to fine tune the operation process and find the optimal position in the diaper to put the wetness sensor to improve the detection rate. We believe that with more trials, the optimal position will be found and usability of the system will be improved that will lead to a high success rate of detection. In the next step, we will test the system on multiple patients concurrently and provide more features such as continence planning that will lead to further improvement in quality of care for the patients

\section{CONCLUSION}

Incontinence and its related problems are pressing problems in eldercare and must be resolved efficiently in order to enhance the quality of life of elderly and care-givers. A smart wireless continence management system based on the mote platform is designed to address the needs based on the requirements of the stakeholders. Preliminary results from a trial of the continence management system in a nursing home for dementia patients with continence problems are very encouraging. The next step is to improve the functionality and usability of the system and the current incontinence management practices for better quality of care.

\section{ACKNOWLEDGMENT}

This research work has been partially supported by American Alzheimer's Association under Everyday Technology for Alzheimer's Care award no. ETAC-07-59979. We would like to express our acknowledgements to Dr. David Craig, Dr. Anthony Peter Passmore and Dr Zhang Daqing for their suggestions, and all the medical staffs, care-givers and patients who have participated in nursing home trials.

\section{REFERENCES}

[1] Christopher M. Tarnay and Narender N. Bhatia, "Urinary Incontinence Overview", Armenian Medical Network, 2006 http://www.health.am/gyneco/urinary-incontinence

[2] Philip Yap and David Tan, "Urinary Incontinence in Dementia: A practical Approach", Australian Family Physican, Vol. 35, No.4, pp: 237-241, Apr 2006

[3] Malem M07 Wireless Enuresis Alarm, http://www.malem.co.uk

[4] Dri-Sleeper Bedwetting Treatment Alarm, http://www.dri-sleeper.com.

[5] H. Wu and M. Siegel, "Odor-based Incontinence Sensor", Proc. of the $17^{\text {th }}$ IEEE Instrumentation and Measurement Technology, Vol. 1, pp. 63 68, May 2000.

[6] J. Siden, A. Koptioug and M. Gulliksson, "The "smart" Diaper Moisture Detection System", Microwave Symposium Digest, IEEE MTT-S International, Vol. 2, pp: 659-662, 2004

[7] J. Hill and D. Culler. "Mica: A Wireless Platform for Deeply Embedded Networks", IEEE Micro Vol. 22, No. 6, pp. 12-24, 2002. 